\title{
CERTIFICATION AND ITS IMPACT ON QUALITY OF CHARITIES
}

\author{
Katarína Svítková*
}

\begin{abstract}
:
Nonprofit organizations in transition countries experience low trust and consequently low income from donations. The study introduces one particular solution to the problem, certification, and examines its impact on the quality of the nonprofit organizations in the market. The situation is illustrated in a game theoretical model, with a manager, donor, certifier, and the charity providing a charitable good: for simplicity, charity is either good or bad: A good charity spends all the resources on the charitable good, and a bad one diverts all resources to the private consumption of its manager (for-profit in disguise). We show that for a wide parameter range and for two different disclosure rules, the presence of a certifier in the market increases the incentives for managers to choose good charities, leading to an improvement in the market as the share of good charities increases.
\end{abstract}

Keywords: certification, quality assurance, fundraising, non-profit organizations.

JEL Classification: D71, D82, L15, L31

\section{Introduction}

During two decades from the fall of the command economic system the Central and Eastern European region experienced radical changes on its way towards the market system. The key changes occurred in the areas of ownership and institutional framework (e.g. Estrin et al., 2009), with the underlying change in the perception of freedom: to speak and to associate, to own and to be responsible for one's own life. In result, the fall of communism brought about an establishment, or rather re-birth, of civil society ${ }^{1}$ : There has been a rapid growth in the number of nonprofit organizations active in a variety of fields, with an often turbulent evolution in the sectors over time (for an overview, see e.g. Pospíšil and Hyánek, 2009; Brhlíková, 2004; Frič, 2004; Svítková, 2004). In this paper we evaluate the current situation and identify the key challenges for the non-profit sector.

The key challenges facing the nonprofit sectors in transition countries of the CEE region 20 years after the fall of communism are well summarized in Forbrig's article published

* Anglo-American University, Lázeňská 4, 11800 Prague, Czech Republic (katarina.svitkova (a)aauni.edu).

The author would like to thank Andreas Ortmann, Marc Bilodeau, Randall Filer, Jan Hanousek, Evžen Kočenda, Richard Steinberg and Joel Sobel for their comments. Financial support provided by the Grant Agency of the Czech Republic (402/09/1595) is gratefully acknowledged. The usual disclaimer applies.

1 Some might argue that it was for the lack of these freedoms that the communism fell. The causality is not relevant for the arguments in the paper. 
in the recent USAID NGO Sustainability Index report (USAID, 2010). Forbrig identifies three main challenges: 1 . The need to clearly define the relationship between the sector and the government; 2 . The need to re-focus from the region on the situations in the individual countries because the differences among the countries in the region have grown; 3. Financial viability of the sector after the foreign donors have left and the economic situation in the countries is hit by the economic crisis.

The current paper offers a theoretical analysis of a possible solution addressing the first and the third challenge. These challenges have a common underlying cause: a continued lack of trust in the nonprofit sector and its organizations (e.g. Pospíšil and Hyánek, 2009; USAID, 2010; Hanousek, Kočenda, Svítková, 2010). Lack of trust in the capacity of nonprofits and their ability to deliver services of high quality translates into lower donations and general support from the public, companies and the government. It also serves the government as a justification to continue providing the social services either directly or through its own entities. Nonprofit organizations in the CEE countries are therefore unable to effectively enter into the domains that are typically served by their counterparts in the western countries, in particular health and social services.

The solution we propose and examine in the present study is an establishment of an independent certification agency that evaluates quality of nonprofit organizations that voluntarily apply for certification. As demonstrated in previous studies certification by an independent nonprofit organization is one of the most efficient solutions that help to improve trust in nonprofit organizations (Bekkers, 2003, 2010; Bias, 2010; Svítková and Ortmann, 2006). In previous related work (Svítková and Ortmann, 2006) we explored the design of the certification system, namely, certifier's choice of quality and price as a function of his optimization function. We omitted an important aspect: the possible impact of the certifier on the quality of charities in the market. Thus, we analyzed an adverse selection problem between the donor and a charity, and assumed that the quality of charity is given exogenously. The current paper relaxes this assumption and allows the quality of charities to be determined within the model, i.e. we explore a moral hazard problem. This approach responds to the evidence provided by Bekkers $(2003,2010)$ that certification may have impact on the average quality of charities in the market.

We explore the impact of certification agency on a decision of a manager regarding the quality of the nonprofit organization he runs. The model follows the logic of Akerlof (1982) and illustrates that under a wide parameter range the presence of a certifier in the market increases incentives for managers to run a good charity, leading to an increase in the quality of charities in the market. This presents a strong argument for introduction of certification to the markets with asymmetric information. Certification agency that would have positive impact on trust through increased transparency and accountability (Bekkers, 2003, 2010; Ortmann et al., 2005) and positive impact on quality of organizations would benefit the sectors in CEE countries and help them to address the challenges they currently face.

The article is structured as follows: Section 2 introduces the assumptions of the model, Section 3.1 describes the model, its timing and structure and results. Section 3.2 
summarizes the choice of the charity, Section 3.3 analyzes the decision of the manager, Section 3.4 examines a certification with an alternative disclosure rule. Section 4 concludes.

\section{Assumptions}

We analyze a game with four players: donor, charity, manager, and a certifier. We specify the assumptions on their behavior below. The timing and detailed structure of the game follows in Section 3.

We study the decision of one representative manager, who chooses the quality of the organization he runs to maximize his utility. The manager is uniquely identified by his preference for the provision of a charitable good, $\alpha$, a random variable with uniform distribution on the unit interval $[0,1] .^{2}$

We assume that the utility function of the manager is a convex combination of private consumption, $X$, and a charitable good, $Q$. Thus, $U(X, Q)=\alpha Q+(1-\alpha) X$. We assume that the manager maximizes his utility subject to a budget constraint and that the only source of revenues for the charity is fundraising, i.e., received donations net of the costs of fundraising.

For simplicity, we assume that the charity can be of two types only: 'good' with quality 1 , or 'bad' with quality 0 . The manager of the organization chooses the type to maximize his utility. A good charity cares about the provision of the charitable good and spends all collected available resources on its provision. A bad charity is a 'for-profit in disguise' (Weisbrod, 1988) that exists to maximize the income of its manager by abusing the nonprofit status and trust of donors, and therefore it does not spend any resources at all on the provision of the charitable good.

The charity decides whether to apply for certification (which is costly). If there is no certification in the market, the charity has no decision to take. The charity maximizes its expected net revenue, therefore, tries to attract as many donations as possible. How it spends the money depends on the type of the charity and, ultimately, on the preference of the manager.

The expected quality of the charities in the market, denoted $d$, is defined by the preference of the manager, who is indifferent between choosing a good or a bad charity, we denote $\operatorname{him} \alpha_{I}$ : managers with higher preference for charitable good, $\alpha>\alpha_{I}$, will set up a good charity, managers with lower preference, $\alpha<\alpha_{I}$, will set up a bad charity. Hence, $d=1-\alpha_{I}$. Thus, to observe the impact of certification on the quality of charities in the market, we compare this 'indifferent' manager in a market with and without certification.

2 This assumption is a simplified version of the assumption of heterogeneity of nonprofit managers, see Young (1983). 
The certifier chooses the certification fee, $c,{ }^{3}$ and the detection technology, $p$, to evaluate the applying charities. In the present study, we do not analyze how the certifier makes this decision; we examine how these parameters affect the choices of the other players. ${ }^{4}$ The results we present are therefore dependent on these parameters. We assume that the certifier is honest and as such the certifier issues a certificate to the charities that apply for certification, pay certification fee, and pass the evaluation.

We assume, in line with what we observe (Guet, 2002), that the certifier evaluates charities on a number of indicators but he summarizes the result into a single number in the interval $[0,1]$. The number represents the observed quality of the charity, as we assume only a good or a bad charity, the number represents the probability that the charity a good one. Certifier's observation is uniquely determined by the quality of the detection technology, $p$ (the probability that a charity is awarded the certificate when it is entitled to): A good charity is awarded the certificate with probability $p$, the bad charity is awarded the certificate by mistake, i.e., when it is not entitled to, with probability $1-p .{ }^{5}$ We assume that the probability of a mistake is smaller than the probability of correct identification, $p \in[1 / 2,1] .{ }^{6}$ With perfect detection, $p=1$, the certifier would identify the good charity as good without mistakes, i.e. he would observe the true quality. Based on this probability the certifier awards or rejects to award the certificate.

We assume one representative donor. ${ }^{7}$ She has a budget normalized to 1 and she decides how much to donate to maximize her utility from the charitable good she cares about. The donor cannot observe the quality of the charitable good, but she realizes it depends on the quality of the providing charity. Specifically, the donor understands that supporting a

3 The existing certification agencies typically charge a fee that increases in the size of the organization. It is typically composed of a fixed and a proportional part, Guet (2002). Thus, we can assume $c$ is a fee for a charity of 'unit' size and as such it remains constant.

4 For an analysis of a certifier's choice for various objective functions see Svítková and Ortmann (2006).

5 We assume, for simplicity, that the detection technology is symmetric, i.e. the probability that a good charity is evaluated as good is equal to the probability that a bad charity is evaluated as bad. We maintain this assumption, because we think that what matters in evaluation is the distance from the standard, and not the direction of this difference: it is difficult to observe quality of charities at the standard, but it is easy to discover the very good or very bad organizations.

6 The probability of correct identification, $p$, is derived from a detection procedure: Let $\varepsilon$ denote the range of possible qualities the certifier may assign to a charity he evaluates. $\varepsilon$ represents the 'mistakes' in the evaluation, the difficulty to observe the true values. We assume that a good charity is evaluated as good with probability distributed uniformly in the interval $[1-\varepsilon, 1]$, a bad charity is assigned probabilities in the interval $[0, \varepsilon]$. We assume $\varepsilon \in[1 / 2,1]$. The best technology, $\varepsilon=1 / 2$, ensures that the certifier is certain about the quality of the evaluated charity, otherwise, he makes mistakes. From the assumption that the observable quality is distributed uniformly follows $p=1 / 2 \varepsilon$ and $1-p=1-1 / 2 \varepsilon . \varepsilon \in[1 / 2,1]$ implies $p \geq 1 / 2$, i.e. a good charity is awarded the certificate more often than a bad one for all detection technologies.

7 Assuming a representative donor avoids the problem of free riding, which often occurs in fundraising. We use this simplifying assumption to be able to focus on the moral hazard problem. 
bad charity means no provision of the charitable good, while supporting a good charity means the highest quality and amount of the charitable good. ${ }^{8}$

The donor cannot observe the quality of the charity she wants to support; she is only able to observe its expected quality. Donor's utility, and hence her donation, therefore depends on the expected quality of the charity, $U_{D}(p)$. We assume that the donation (giving) is identical to the utility obtained from supporting a charity with expected quality $p, g(p)=U_{D}(p)$. Donor's utility increases in the expected quality of the charity, $U_{D}{ }^{\prime}(p)>0$, it is maximized when she supports a good charity, $U_{\mathrm{D}}(1)=U_{\max }=1$ (the maximum is normalized to 1 , the maximum donations she can give), and it is zero when she would support a bad charity, $U_{D}(0)=U_{\min }=0$.

In a market without certification the donor knows only the average quality of the charity in the market. Due to this asymmetric information problem, she donates less than she would if she knew the charity was good.

In a market with certification the donor obtains additional information: she observes also whether the charity has the certificate, and she knows the certification fee and quality of the detection technology. ${ }^{9}$ The donor uses this information to update her prior beliefs about the quality of the charity, and gives accordingly. If the certifier ensures that only a good charity receives the certificate, the donation to the certified charity is the highest possible, $1 .{ }^{10}$ However, even in this case, a non-certified charity receives a positive donation too. This is caused by the fact that there are mistakes in the evaluation technology and therefore even a good charity may be rejected a certificate (by mistake). The donor cannot distinguish whether the charity does not have a certificate because it did not apply or because it applied but failed the evaluation (due to a mistake). ${ }^{11}$

With the worst detection technology, $p=1 / 2$, the probability that a good charity receives the certificate is equal to the probability that a bad charity receives it. The probability that a good charity fails to pass the evaluation is the highest possible, and the donor makes the smallest difference in her support of certified and non-certified organizations. With perfect detection, $p=1$, a good charity is always awarded the certificate. The donor relies

8 The assumption that donors appreciate quality is based on empirical evidence from the Netherlands, where donors increased their giving to certified charities after they learned about the certification (Bekkers (2010); Bekkers (2003)). An alternative assumption would be that donors want to maximize provision of the charitable good, not caring for quality of charities (it is necessary to give more to less efficient organizations, because they need more funds to provide the same result as good charities). But, then the donors would give most to the bad charity and gain no provision at all, which seems very unusual and contradicts the empirical evidence obtained in the Netherlands.

9 We assume that the certifier does not disclose any additional information about the certification, the donor obtains only a binary signal: certificate/no certificate. This assumption is based on the observed reality Guet (2002). In Section 3.4 we analyze a case with an alternative disclosure rule, where the donor observes also whether the charity applied for certification.

10 The certifier is in reality never able to ensure perfect detection. We discuss the case for the theoretical purposes only.

11 This assumption is in line what we observe in certification markets, Guet (2002). 
on the signal and gives a donation to the certified charity only, the difference between her support of a good and a bad charity is the highest, 1 .

\section{Model and Results}

\subsection{Timing of the game}

1. Preference of the manager, $\alpha$, is randomly drawn from a uniform distribution over $[0,1]$. The conditions of the certification system are set: the fee for certification, $c$, and the quality of detection technology, $p$.

2. The manager chooses quality of the charity he runs, he decides between a good charity, of quality 1 , and a bad one, of quality 0 , maximizing his utility function.

3. The charity chooses whether to apply for certification maximizing its expected net revenues.

4. If the charity has applied for certification, the certifier evaluates it and awards the certificate if it passes the evaluation.

5. The donor adjusts her beliefs about the quality of the charity based on the information she receives: whether the organization has been certified, the certification fee, and the quality of detection technology. She gives accordingly.

We solve the game in two steps. First, we solve for the optimal strategy of the charity in the subgame between the charity and the donor given the certification system. Second, we solve the full game, identifying the equilibrium strategy of the manager, and the indifferent manager $\alpha_{I}$. For comparison we start with the benchmark case - the market without certification.

\subsection{Decision of a charity}

\subsubsection{No certification}

In the market without certification the donor knows the probability that the charity is good, $d_{N C}{ }^{12}$ She cannot observe the true quality of the charity, and therefore gives according to her expectations, $g\left(d_{N C}\right)$. In this case the charity does not have any decision to make.

\subsubsection{Certification}

In the market with certification a charity decides whether to apply for certification and send the donor a signal about its quality. If it applies for certification, it goes through the evaluation and obtains the certificate with probability $p$ if it is a good charity, and probability $1-p$ if it is a bad charity. The charity chooses the strategy that ensures higher

12 This is a realization of the variable $p$, it describes the actual situation in the market, the choice of the charity as a result of manager's preferences. 
expected payoff. The subgame has four types of equilibria: A separating equilibrium, in which only the good charity applies, a pooling equilibrium, in which both types apply, a pooling equilibrium in which the good charity applies and the bad one applies with a positive probability, and a pooling equilibrium, in which both types do not apply.

The separating equilibrium arises if only the good charity applies for certification and the bad charity does not apply. The equilibrium is characterized by the following incentive compatibility constraints:

$$
\begin{aligned}
& \mathrm{E}[\mathrm{A} \mid 0] \leq E[\mathrm{NA} \mid 0] \leftrightarrow(1-p)+p g_{N C}-c \leq g_{N C} \\
& \mathrm{E}[\mathrm{A} \mid 1] \geq E[\mathrm{NA} \mid 1] \leftrightarrow p+(1-p) \mathrm{g}_{N C}-\mathrm{c} \geq \mathrm{g}_{N C}
\end{aligned}
$$

Constraint (1) requires that the bad charity is better off not applying (NA) for certification. Constraint (2) requires that the good one is better off applying (A). In this separating equilibrium, the charity with the certificate is known to be of quality 1 , thus, it obtains the highest possible payoff, 1 . The non-certified charity can be either good or bad, its payoff $g_{N C}$ depends on the probability that it is good, $g_{N C}=g(\operatorname{Prob}[1 \mid N C])$. This probability is:

$$
\operatorname{Prob}[1 \mid N C]=\frac{\operatorname{Prob}[1] \operatorname{Prob}[N C \mid 1]}{\operatorname{Prob}[0]+\operatorname{Prob}[1] \operatorname{Prob}[N C \mid 1]}=\frac{d(1-p)}{1-d p}
$$

Where $d$ denotes the initial probability that the charity in the market is good.

Simplifying and rearranging the constraints (1) and (2) we derive that the certification fee $c$ within the following range leads to a separating equilibrium:

$$
c_{\min }=(1-p)\left(1-g_{N C}\right) \leq c \leq p\left(1-g_{N C}\right)=c_{\max }
$$

Intuitively, the certification fee that induces separation increases as the difference in the payoff to the certified and non-certified charity increases because an increase in this difference means that the incentives for the bad type to apply for certification are higher. The certifier decreases these incentives by increasing the costs of certification, i.e. charging a higher fee. The quality of the detection technology, $p$, increases the range of fees the certifier may charge. A certifier with perfect technology, $p=1$, may charge any fee in the interval $[0,1]$ and still induce separation because he relies solely on evaluation and not on the fee. With technology of lower quality the certifier's reliance on the fee increases and the range of fees leading to separation is smaller. The worst technology, $p=1 / 2$, leaves no choice - the only fee inducing separation is $c=\frac{1}{2}\left(1-g_{N C}\right)$.

If the certifier charges a fee below $c_{\min }$, the incentive compatibility constraint for the bad type (1) is not satisfied. In this case, the game has two types of equilibria: a pooling equilibrium, in which both types of charity apply for certification, and an equilibrium in mixed strategies, with the good charity always applying and the bad charity applying with a positive probability.

In the pooling equilibrium, both types apply for certification and are evaluated; the good charity receives the certificate with higher probability. The donor evaluates the expected 
probability that a charity with and without the certificate is good, and gives accordingly. The payoffs in the pooling equilibrium are the following: ${ }^{13}$

$$
\begin{gathered}
g_{C p}=g\left(\frac{d p}{d p+(1-d)(1-p)}\right) \\
g_{N C p}=g\left(\frac{d(1-p)}{d(1-p)+(1-d) p}\right)
\end{gathered}
$$

The participation constraints defining the pooling equilibrium look as follows:

$$
\begin{gathered}
(1-p) g_{C p}+p g_{N C p}-c \geq g_{N C p} \\
p g_{C p}+(1-p) g_{N C p}-c \geq g_{N C p}
\end{gathered}
$$

Constraint (7) ensures participation of the bad type. Because the expected payoff of the bad type is always below that of the good type, the good type participates whenever the bad type does (constraint (8) is satisfied). We denote the fee at which the constraint (7) binds $c_{\max , p}$.

If the certifier charges a fee in the interval $\left[c_{\max , p}, c_{\min }\right]$, there does not exist an equilibrium in pure strategies. While the good charity always applies, the bad one chooses to apply with some probability (less than one).

If the certifier charges a fee above the maximum fee guaranteeing separation, $c_{\max }$, then neither bad nor good type applies for certification. Certification in this case has no effect on the situation in the market and we do not need to consider this case any further.

Figure 1 summarizes the different type of equilibria arising in the market as a function of the certification fee. The equilibrium is described by the choice of the good charity, and the choice of the bad charity to apply (A) or to not apply (NA).

Figure 1

Different Types of Equilibria Arising in the Market as a Function of the Certification Fee

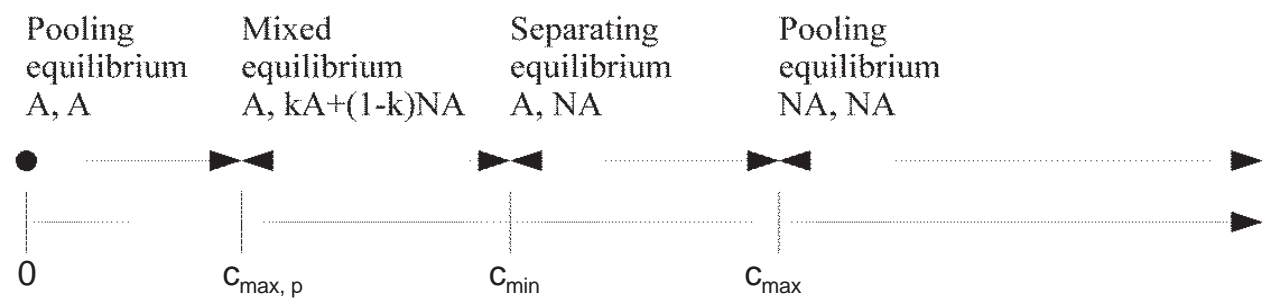

$$
\begin{aligned}
& g_{C p}=g(\operatorname{Prob}[1 \mid C])=g\left(\frac{\operatorname{Prob}[1] \operatorname{Prob}[C \mid 1]}{\operatorname{Prob}[1] \operatorname{Prob}[C \mid 1]+\operatorname{Prob}[0] \operatorname{Prob}[C \mid 0]}\right) \\
& g_{N C p}=g(\operatorname{Prob}[1 \mid N C])=g\left(\frac{\operatorname{Prob}[1] \operatorname{Prob}[N C \mid 1]}{\operatorname{Prob}[1] \operatorname{Prob}[N C \mid 1]+\operatorname{Prob}[0] \operatorname{Prob}[N C \mid 0]}\right)
\end{aligned}
$$




\subsection{Decision of the manager}

In this section we analyze the manager's choice of the quality of the organization he runs. We identify the manager who is indifferent between running a good or a bad charity, $\alpha_{I}$, defining the quality of the organization in the market, $d ; d=1-\alpha_{I}$. We first consider the benchmark case without certification, $d_{N C}$, then we observe how it changes in a market with certification, $d_{C}$.

The manager chooses the type of organization that maximizes his utility, comparing:

$$
\begin{gathered}
U(X, Q \mid 0)=(1-\alpha) X ; \text { s.t. }: E[. \mid 0] \geq X \\
U(X, Q \mid 1)=\alpha Q ; \text { s.t. : } E[. \mid 1] \geq Q
\end{gathered}
$$

The bad charity spends all collected donations on manager's private consumption, generating utility $(1-\alpha) X$. The good charity spends all collected donations on provision of the charitable good, generating utility $\alpha Q$. The expected payoffs of the charity, E[.|0 or 1], were defined in the previous sections (equations (1) and (2)).

\subsubsection{No certification}

In the market without certification the donor cannot distinguish between a good and a bad charity, she gives according to the expected probability that the charity is good. The payoffs to the two types are therefore equal. With the uniform distribution of manager's preferences, the indifferent manager is the one in the middle: $\alpha_{\mathrm{NC}}=1-d_{N C}=1 / 2=d_{N C}$.

\subsubsection{Certification}

The impact of certification on the decision of the manager, $\alpha_{C}$, and thus the quality of the charity in the market, $d_{C}$, depends on the detection technology, $p$, and the certification fee, $c$. The following proposition specifies.

\section{Proposition:}

Certification with a fee below $c_{\max , p}$, increases the expected quality of the organization in the market, $d_{C}>d_{N C}$, for all detection technologies with $p>1 / 2$. The impact increases in the fee, $c$. An improvement of the detection technology, $p$, increases the expected quality.

Certification with a fee in the interval $\left[c_{\max , p}, c_{\min }\right]$, leading to the mixed equilibrium, increases the expected quality of the organization in the market, $d_{C}>d_{N C}$. The impact decreases in the fee, $c$. 
Certification with a fee in the interval $\left[c_{\min }, c_{\max }\right]$, leading to the separating equilibrium, increases the expected quality of the organization in the market, $d_{C}>d_{N C}$, for all detection technologies with $p>1 / 2$. An increase in the certification fee within the interval decreases the expected quality. An improvement of the detection technology, $p$, increases the expected quality.

Certification with a fee at and above $c_{\max }$ has no impact on the quality of the organization in the market, $d_{C}=d_{N C}$, for all qualities of detection technology. Similarly, certification with the worst detection technology, $p=1 / 2$, has no impact on the quality of the organization in the market. The result does not depend on the fee.

Certification with a fee below $c_{\text {max }, p}$ leads to a pooling equilibrium (see Section 3.2.2). Certification in this case, despite the fact that both types apply for certification, brings additional information because the certifier awards the certificate more often to the good charity. The donor, therefore, ends up giving more to the good charity. The difference in the payoff to the good and the bad charity increases in the quality of detection technology, as better detection means that the probability of good charity having the certificate is higher. An increase in the certification fee has the same effect on the payoffs of both charities, but because the probability that a bad type receives the certificate is lower, his expected payoff is lower. An increase in the certification fee, though, has a different impact on the utility of managers running good and bad charities. The difference depends on his preference for the charitable good, $\alpha$. Managers with $\alpha<1 / 2$ running a bad charity, i.e., getting utility $(1-\alpha) X$, suffer more from the increase of the fee than managers with higher $\alpha$. Therefore, increasing the fee decreases the incentives to start a bad charity for managers with low preference for the charitable good, the effect is the strongest at the highest fee ensuring pooling equilibrium, $c_{\max , p}$. The effect increases in the quality of the detection technology as illustrated in Figure 2 below, the dashed line.

Certification with a fee in the interval $\left[c_{\min }, c_{\max }\right]$, see (4), leads to a separating equilibrium. In this case only the utility of the manager choosing a good charity decreases in the fee for certification. Utility of the manager running a bad charity is not directly affected by the fee because the bad charity does not apply for certification. The difference in the payoff to the good and the bad charity decreases as the fee increases. Therefore, it is sufficient to consider the effect of certification in the two polar cases, when the certifier charges the highest and the lowest fee leading to separation.

If the certifier charges the highest fee (the good charity is indifferent between applying and not, the incentive compatibility constraint (2) holds with equality), he extracts the whole surplus the charity gains from the certificate. The expected payoff of the charity with the certificate, and therefore the utility from running such a charity, is the same as it would be in the market without certification. This certification therefore has no impact on the quality of the charity in the market; i.e. the probability that a charity is good, $d_{C}$, and, the indifferent manager $\alpha_{C}$, remain the same. The result is independent of the detection technology, $p$. The only service provided by the certifier is the information provided to the donor, who learns something about the charity she 
supports. Nevertheless, this has no effect on the final provision of the charitable good because, even though the donor gives more if she learns that the charity is good, the surplus donation ends up in the pocket of the certifier.

If the certifier charges the lowest fee ensuring separation (the bad charity is indifferent between applying and not, the incentive compatibility constraint (1) holds with equality), the utility from running a good charity is significantly above that from running a bad one because the certifier leaves the surplus brought by the certificate to the charity. Therefore, even a manager with a weaker preference for the charitable good prefers to run a good charity. The analytical solution defining $\alpha_{C}$, thus $d_{C}$, exists but it does not have any intuitive form, therefore, we illustrate it in Figure 2, the full line. ${ }^{14}$ The probability that a charity is good is higher than in the benchmark market with no certification, i.e., the indifferent manager has lower preference for the charitable good.

The result is valid for all detection technologies, but the impact of certification (the difference between $d_{N C}=1 / 2$ and $d_{N C}$ ) varies: Certification with the worst detection technology, $p=1 / 2$, has no impact on the market, the probability that the charity is good is the same as in the market with no certification. ${ }^{15}$ As the quality of detection increases the probability that a charity is good increases. As the quality of detection approaches its maximum, $p \rightarrow 1$, probability that the charity is good approaches 1 , $d_{C} \rightarrow 1$, i.e., $\alpha_{C} \rightarrow 0$, a manager with any preference chooses to run a good charity. Intuitively, with perfect detection the good charity applies for certification and obtains the certificate with certainty. Thus, the probability that there is a good charity among the non-certified is 0 , and the non-certified charities receive no donation. The manager with any preference, therefore, has no incentive to run such charity.

Figure 2

Probability that the Charity Is Good, d, as a Function of the Quality of Detection Technology, p; Full Line: Separating Equilibrium; Interrupted Line: Pooling Equilibrium

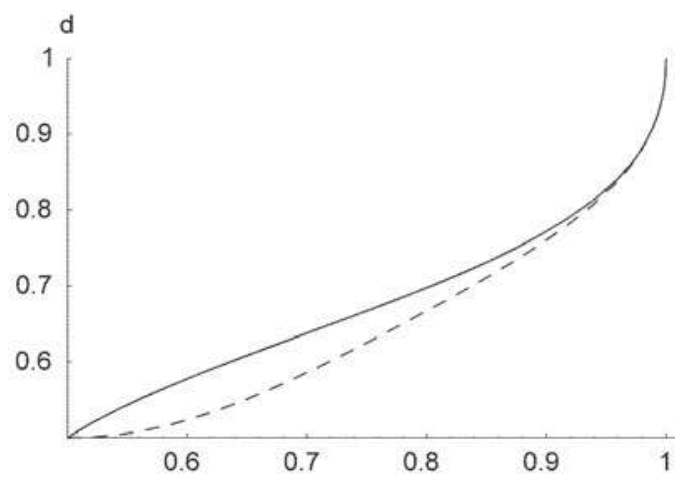

14 Analytical solutions are available on request from the author.

15 This results from the fact that with the worst technology the certifier relies solely on the certification fee to induce separation of good and bad organizations, there is only one fee he can charge. He leaves no surplus for the good charities, and hence no additional incentives for managers to start a good charity. 
Figure 2 depicts the impact of certification in the pooling and in the separating equilibrium at the fees that ensure the highest effect: for the pooling equilibrium at the highest, for the separating at the lowest possible fee. For all detection technologies the impact is stronger in the separating equilibrium (full line). The intuition is the following: At the lowest fee ensuring separation the bad organization does not apply for certification because its expected payoff is too low to cover the costs of certification. Certification at this point fully uses both tools it has to separate the organizations, certification fee and detection technology. Increasing the fee beyond the minimum decreases the payoff only for the good charity and makes it less appealing to run a good charity. Decreasing the fee towards the pooling equilibrium increases the payoff for the bad type, increasing the incentives for the manager to choose this type of charity.

\subsection{Alternative disclosure rule}

In this section we examine the impact of a certification with an alternative disclosure rule: the certifier discloses to the donor not only who has the certificate $(\mathrm{C}, \mathrm{NC})$, but also who has applied for certification (A, NA). ${ }^{16}$ Thus, the donor distinguishes three types of charity: charity that applies and receives the certificate, it receives a donation $g_{A C}$, charity that applies and fails to receive the certificate, $g_{A N C}$, and charity that does not apply, $g_{N A}$. This alternative disclosure rule is appealing because it seems that it may lead to perfect separation: if only the good charity applies for certification and the donor knows about it, giving to the bad charity drops to zero and giving to the good non-certified charity increases. Nevertheless, none of the certification agencies operating in fundraising markets (Svítková and Ortmann, 2006; Guet, 2002) uses this type of disclosure.

First, we examine the existence of the separating equilibrium, as we expect the new disclosure to have the strongest effect in this case. In the separating equilibrium only the good charity applies for certification, it passes the evaluation and receives the certificate with probability $p$ and fails with probability $(1-p)$. Because the donor observes also who has applied for certification and who has not, and knows that the bad charity never applies, she gives nothing to the charity that has not applied for certification, and 1 to the charity that has applied for certification regardless of the result, i.e. charity with and without the certificate receives the same donation. But, this presents very strong incentive for the bad charity to apply: even if it fails the evaluation the donor would consider it good because she relies on the apply/not apply information and not on the result of evaluation. Thus, the bad type also applies, the certifier is not able to stop him because the donor makes no difference between the certified and non-certified charity, hence the separating equilibrium does not exist. In terms of the incentive compatibility constraints:

16 We thank Randall Filer for pointing out to this alternative. 


$$
\begin{aligned}
& E[A \mid 0] \leq E[N A \mid 0] \Leftrightarrow(1-p) g_{A C}+p g_{A N C}-c \leq g_{N A} \\
& E[A \mid 1] \geq E[N A \mid 1] \Leftrightarrow p g_{A C}+(1-p) g_{A N C}-c \geq g_{N A}
\end{aligned}
$$

These two conditions simplify to the following condition on the fee to be charged:

$$
(1-p) g_{A C}+p g_{A N C}-g_{N A} \leq c \leq p g_{A C}+(1-p) g_{A N C}-g_{N A}
$$

In the separating equilibrium only the good type applies for certification, the payoff to the charity that does not apply, $g_{N A}$, is zero, and the payoffs $g_{A C}$ and $g_{A N C}$ are equal. Thus, condition (13) leaves no room for separation.

In the pooling equilibrium, we assume that the donor maintains her belief that the charity that does not apply for certification is bad, thus, the payoff $g_{N A}$ is zero. This is the major difference between the two certification systems, as in the system with the original disclosure rule the charity that did not apply for certification could not be distinguished from a charity that applied and failed, thus, it received a positive payoff. Because the 'outside' option in this case is zero, the pooling equilibrium exists for a larger range of fees than before. We denote the maximum certification fee for which the pooling equilibrium exists $c_{\max , a}$, it is defined by the following constraint holding with equality: ${ }^{17}$

$$
(1-p) g_{A C}+p_{A N C}-c \geq g_{N A}=0
$$

The payoffs to the certified and non-certified charity remain the same as in the original system, see Section 3.2. ${ }^{18}$ The pooling equilibrium exists for a larger range of fees than in the original system, $c_{\max , a} \geq c_{\max , p}$. Moreover, there exists a detection technology, denoted $p_{\max }$, above which the pooling equilibrium exists in the new certification system while the original system leads to a pooling equilibrium with no type applying, $c_{\max , a} \geq c_{\max }$ for $p>p_{\max } \cdot{ }^{19}$

The quality of the organization in the market when both systems lead to a pooling equilibrium, $\mathrm{c} \leq c_{\max , p}$, is the same in both systems. In this case the systems differ only in the out-of-equilibrium payoff to a charity that does not apply for certification; this has no impact on the equilibrium payoffs, thus, the manager's choice.

17 As before, see Section 3.2, the pooling equilibrium exists as long as the bad type participates.

18 The only difference occurs in the out-of-equilibrium payoff, $g_{N A}$. The payoffs to the charities that apply for certification are the same in both cases because they are derived under the assumption that both types apply.

$19 p_{\max }$ increases in the probability that the charity in the market is good: as the probability increases, the payoff to the non-certified charity increases because there is higher probability that there is a good charity. Thus, the 'outside' option for the charity increases, making it more difficult to preserve separation. Also, increasing the probability of the good charity increases the payoff to the good and bad charity in the pooling equilibrium, making the 'outside' option, zero, less attractive. 
In the case when the original certification system leads to a separating and the system with the alternative disclosure leads to a pooling equilibrium, $c_{\min } \leq c \leq \operatorname{Min}\left\{c_{\max , a}, c_{\max }\right\}$, the equilibrium payoffs differ. In the separating equilibrium, the impact of certification is the highest at the minimum fee, $c_{\text {min }}$, which leaves the highest surplus for the good charity while preventing the bad charity from applying. Increasing the fee above $c_{\text {min }}$ leads to a decrease in the surplus of the good charity, decreasing the incentives for the manager to choose a good charity. In the pooling equilibrium in the system with alternative disclosure, increasing the fee has negative effect on the good and the bad charity as they both pay the fee. Therefore, the surplus donation to the good charity, thus, the incentive to choose a good charity, decreases more slowly than in the separating equilibrium. The difference decreases also as the quality of detection increases, as detection is the main source of information in the pooling equilibrium. Therefore, for fees above $c_{\text {min }}$ there exists a detection technology $p_{a}$ above which the new certification ensures higher quality of organizations in the market. ${ }^{20}$

In the case when the original certification leads to a pooling equilibrium with no type applying for certification, and the new certification leads to a pooling equilibrium with both types applying, $c_{\max } \leq \mathrm{c} \leq c_{\max , a}$, the original system has no impact on the quality in the market, while the new system increases quality. If the certification fee is too high (above 1), the alternative disclosure also leads to a pooling equilibrium with no type applying for certification. This is the same situation as in the original system with the fee above $c_{\max }$.

The choice of the certifier depends on the budget he has available, the costs of the detection technology, and his objective function. But, if the certifier wants to reach the highest improvement of quality in the market, he shall charge the lowest fee that leads to separation, $c_{m i n}$, and keep the original disclosure rule. He shall turn to the alternative disclosure only if he was forced to charge a higher fee. This may occur, for example, if the technology costs too much.

\section{Conclusion}

In the present study we modelled the impact of certification on the quality of organizations in the market. We showed that the certifier is able to increase the quality by increasing the incentives for the managers to choose a good charity. This result presents a strong argument for the introduction of a certification agency to a market with asymmetric information, i.e. markets with low trust and transparency as observed in the transition countries. The certifier minimizes the negative impact of the asymmetric information by offering a credible signal which allows the good charities to distinguish themselves from the bad ones, donors follow this signal and increase their support to the (identified) good charities. More funding available for the good charities motivates even managers with lower preference for charitable good to start

20 This quality remains below the quality ensured by the separating equilibrium with minimum fee, $c_{m i n}$. 
a good charity, decreasing the number of bad charities in the market and gradually improving the quality in the market.

The design of the certification system is crucial for the success of the initiative: We illustrated that the impact of certification depends on the choice of the detection technology and certification fee-different combinations of the two aspects lead to different equilibria, which in turn have different effects on the behavior of managers. Specifically, if the fee is too low, both types of charity apply for certification and the certifier relies solely on the evaluation to distinguish the good organization from the bad one. With a higher fee, it becomes too costly for the bad type to apply for certification: A separating equilibrium arises in which only the good type applies. If the certifier increases the fee further, it becomes too costly even for the good type, and no type applies for certification. The impact on quality is strongest with the lowest fee ensuring separation of good and bad. At this point, the bad charity has no interest in applying, while the good charity is left with the highest surplus for its operation. The impact increases in the detection technology: an improvement of technology increases the difference in the payoff to the certified and the non-certified charity, increasing the incentives for the manager to choose a good charity.

The disclosure rule is another factor that affects the impact of the certification system: we illustrated that the standard Certified/Non-certified disclosure rule can lead to separation of the good and bad charities, while the alternative Did-not-Apply/ Applied//Certified/Non-certified disclosure rule cannot. Certification with the standard disclosure rule therefore has larger positive impact on quality in the market. However, under specific circumstances, e.g. too high certification fees leading to a pooling equilibrium with the standard disclosure, the alternative rule may offer better results and might be preferred.

These results prove that there is a mechanism that can help the nonprofit organizations in the transition countries build trust and improve their relationship with the stakeholders. According to the results, the optimal design of the certifier recommends that he shall charge for the services, but the fee must be kept rather low and he must distinguish the organizations primarily using a good detection technology. This is a sound solution that has a potential to be accepted by the market as well: if the fee would be too high, it would be prohibitively high for the nonprofits and it would be considered unethical by the donors (who want to support nonprofit's cause and not quality assurance). To gain broad acceptance by the public, the simple disclosure Certified/Non-certified shall be supplemented by transparent behavior of the certified organizations. This will allow the stakeholders to assess their results themselves, shall they be interested, but will allow them to rely on the certificate, shall they choose to do so.

The implications of the model can be further strengthened by further generalization of the model: assuming a continuum of charities with different qualities or consider different giving behavior of the donor. The model can be also extended to consider the choice of the certifier and consider alternative certifiers, who would be limited in their operations by different budget constraints. 


\section{References}

Akerlof, G. A. (1982), "Labor Contracts as Partial Gift exchange." The Quarterly Journal of Economics, Vol. 97, No. 4, pp. 543-569.

Bekkers, R. (2003), "Trust, accreditation, and Philanthropy in the Netherlands." Nonprofit and Voluntary Sector Quarterly, Vol. 32, No. 4, pp. 596-615.

Bekkers, R. (2010), "The Benefits of Accreditation for Fundraising Nonprofit Organizations in the Netherlands," in Gugerty M.K., Prakash A., eds., Nonprofit Clubs: Voluntary Regulation of Nonprofit and Nongovernmental Organizations. Cambridge: Cambridge University Press.

Bies A. (2010), "Evolution of Nonprofit Self-Regulation in Europe." Nonprofit and Voluntary Sector Quarterly, Vol. 39, No. 6, pp. 1057-1086.

Brhlíkova, P. (2004), "The Nonprofit Sector in the Czech Republic. "CERGE-EI Discussion Paper No. 2004 - 128. Prague: CERGE-EI.

Estrin, S., Hanousek, J., Kočenda, E., Švejnar J. (2009), "Effects of Privatization and Ownership in Transition Economies." Journal of Economic Literature, Vol. 47, No. 3, pp. 699-728.

Forbrig, J. (2010), "'Never Waste a Good Crisis': The 2008 Economic Downturn and Post-Communist Civil Society," in: The 2009 NGO Sustainability Index for Central and Eastern Europe and Eurasia, USAID.

Frič, P. (2004), "Political Developments after 1989 and Their Impact on the Nonprofit Sector." Mimeo, Prague: UK FSV CESES.

Guet, I. H. (2002), "Monitoring Fundraising. A Comparative Survey of ICFO Members and Their Countries." Technical report, ICFO, Berlin.

Hanousek, J., Kočenda, E., Svítková, K. (2010), "Corporate Philanthropy in the Czech and Slovak Republics." Finance a Úvěr, Vol. 60, No. 2, pp. 102-121.

Ortmann, A., Svítková, K. and Krnáčová, A. (2005), "Certification as a Viable Quality Assurance Mechanism in Transition Economies," in: Feasibility Study on Establishing a Certification System for Nonprofit Organizations in the Czech Republic. Prague: Transparency International Czech Republic, pp. 7-46.

Pospíšil, M., Hyánek, V. (2009), "Country-Specific Situation of the Nonprofit Sector in the Czech Republic." Unpublished manuscript, CVNS.

Svítková, K. (2004), "The Evolution of the Third Sector in Slovakia." CERGE-EI Discussion Paper No. 2004-122. Prague: CERGE-El.

Svítková, K., Ortmann, A. (2006), "Certification as a Viable Quality Assurance Mechanism: Theory and Suggestive Evidence." CERGE-EI Working Paper No. 288. Prague: CERGE-EI.

USAID (2010), The 2009 NGO Sustainability Index for Central and Eastern Europe and Eurasia. Available at: http://www.usaid.gov/locations/europe_eurasia/dem_gov/ngoindex/2009/, accessed September 28, 2011; 2010.

Weisbrod, B. A. (1988), The Nonprofit Economy. Cambridge, Massachusetts, London, England: Harvard University Press.

Young, D. R. (1983), If not for Profit, for What? Lexington, MA: Heath. 